\title{
THE PERFORMANCE OF LAND USE CHANGE CAUSATIVE FACTOR ON LANDSLIDE SUSCEPTIBILITY MAP IN UPPER UJUNG-LOE WATERSHEDS SOUTH SULAWESI, INDONESIA
}

\author{
A. S. Soma ${ }^{a, b}, T$. Kubota ${ }^{c}$ \\ a Graduate School of Bio-Resources and Environmental Science, Kyushu University, Japan \\ ${ }^{b}$ Faculty of Forestry, Hasanuddin University, Indonesia \\ c Faculty of Agriculture, Kyushu University, Japan
}

Article Info:

Received: 31 July 2017

in revised form: 10 August 2017

Accepted: 10 October 2017

Available Online: 30 October 2017

\section{Keywords:}

Land use change, landslide susceptibility, frequency ratio, logistic regression

Corresponding Author:

Andang Suryana Soma

Graduate School of Bio-Resources

and Environmental Science, Kyushu

University, Japan

Email: suryaandang@kyudai.jp
Abstract: The study aims to develop and apply land use change (LUC) performance on landslide susceptibility map using frequency ratio (FR), and Logistic regression (LR) method in a geographic information system. In the study area, Upper Ujung-loe Watersheds area of Indonesia, landslides were detected using field survey and air photography from time series data image of Google Earth Pro from 2012 to 2016 and LUC from 2004 to 2011. Landslide susceptibility map (LSM) was constructed using FR and $L R$ with nine causative factors. The result indicated that LUC affect the production of LSM. Validation of landslide susceptibility was carried out in this study at both with and without LUC causative factors. First, performances of each landslide model were tested using AUC curve for success and predictive rate. The highest value of predictive rate at with LUC in both FR and LR method were $83.4 \%$ and $85.2 \%$, respectively. In the second stage, the ratio of landslides falling on high to a very high class of susceptibility was obtained, which indicates the level of accuracy of the method.LR method with LUC had the highest accuracy of $80.24 \%$. Taken together, the results suggested that changing the vegetation to another landscape causes slopes unstable and increases probability to landslide occurrence.

Copyright (C) 2017 GJGP-UNDIP This open access article is distributed under a Creative Commons Attribution (CC-BY-NC-SA) 4.0 International license.

\section{How to cite (APA 6th Style):}

Soma, A. A., \& Kubota, T. (2017). The performance of land use change causative factor on landslide susceptibility map in upper Ujung-Loe watersheds South Sulawesi, Indonesia. Geoplanning: Journal of Geomatics and Planning, 4(2), 157-170. doi:10.14710/geoplanning.4.2.157-170

\section{INTRODUCTION}

Land use changes (LUC) has increased the level of vulnerability to landslides, especially in mountainous regions. It is recognized throughout the world as one of the most important factors influencing the occurrence of rainfall-triggered landslides (Glade, 2003). It implies to landslide occurrence on a steep slope (Mugagga, Kakembo, \& Buyinza, 2012).

In South Sulawesi Indonesia, especially in Ujung-Loe upper watershed, LUC has been translated into numerous landslide incidents triggered by the intensity of rainfall compared to other factors such as earthquakes. The topography is extremely steep and naturally mountainous (38.8\% class slope $>20$ degrees). It has a very high level of instability, especially during the rainy season. The rainfall can reach 2,976 to $7,114 \mathrm{~mm} /$ year with average annual rainfall of 4,524 mm/year. Farming which is located in the mountainous area is the primary occupation of social community in that area is. It is hard to avoid this agricultural practice. This has become people's culture for agriculture in mountainous regions and they have made it hereditary (Soma \& Kubota, 2017).

Landslide susceptibility defined as quantitative or qualitative assessment classification, volume (or area), and the spatial distribution of landslides or potentially may occur in the zone. Susceptibility can also include a description of the speed and intensity of existing or potential landslides (Fell et al., 2008). Using scientific analysis of landslides, this study can assess and predict landslide susceptibility and decrease landslide damage through proper preparation (Lee et al., 2002). 
A few studies have evaluated Land Use Change (LUC) that contributed to landslide occurrence (GarcíaRuiz et al., 2010; Glade, 2003; Mugagga, Kakembo, \& Buyinza, 2012; Soma \& Kubota, 2017). However, the use of LUC as a causative factor to see the performance of LUC and to build landslide susceptibility has not yet implemented. Therefore, the LUC will be as a new causative factor to change a land use as a human factor. Land use is simply implemented to look at the current time and different with the LUC. LUC can prepare what land has used before. Example, early land use change was primary forests to farmland, then compared with the open land change to agricultural, of these two conditions have different slope stability (Soma \& Kubota, 2017). Based on these factors, previous researchers have not drawn the performance of land use changes as a causative factor. The objective of the study was to examine the performance of land use change as a causative factor to produce Landslide Susceptibility Map using frequency ratio, logistic regression, and comparison.

\section{DATA AND METHODS}

\subsection{Study Area}

Upper of Ujung-Loe Watersheds was located in Bulukumba and Sinjai Regency, South Sulawesi Province, Indonesia. It provides a fertile land but frequently suffers from landslide disasters. Landslide disasters occur almost every year, especially during the rainy season, which induces flash floods and debris flows in the upstream (Soma \& Kubota, 2017).

The upper of Ujung-Loe Watersheds is located at $119^{\circ} 55^{\prime} 42.34^{\prime \prime} \mathrm{E}$ to $120^{\circ} 8^{\prime} 43.12^{\prime \prime} \mathrm{E}$ and $5^{\circ} 18^{\prime} 19.07^{\prime \prime}$ $S$ to $5^{\circ} 24^{\prime} 43.33^{\prime \prime} S$ with the altitude of $255-2,860$ meters above sea level with areas of $79.79 \mathrm{~km}^{2}$ (Figure 1). It provided forests covering an area of cultivation and farming. Some areas are particularly in the upstream part. According to geological maps of Sulawesi, it is dominated by Volcanic Rock of Lompobatang (Qlv and Qlvc) and Members of Volcanic Breccia rocks of Lompobatang (Qlvb). The volcanic rocks of Lompobattang Mountain consist of Extrusive, mafic, and polymict, which form a broad stratovolcano and quarter lompobattang volcanic estimated start from the last of Pliocene to early Pleistocene of volcanic rock. Members of Volcanic Breccia rocks of Lompobatang (Qlvb) consist of Extrusive, mafic, and polymict, and are estimated to start from first Pleistocene to early Holocene of volcanic rock. The slope is around $38.8 \%$ with slope class $>20$ degrees including a particular area at the upstream is very steep ( $>40$ degrees).

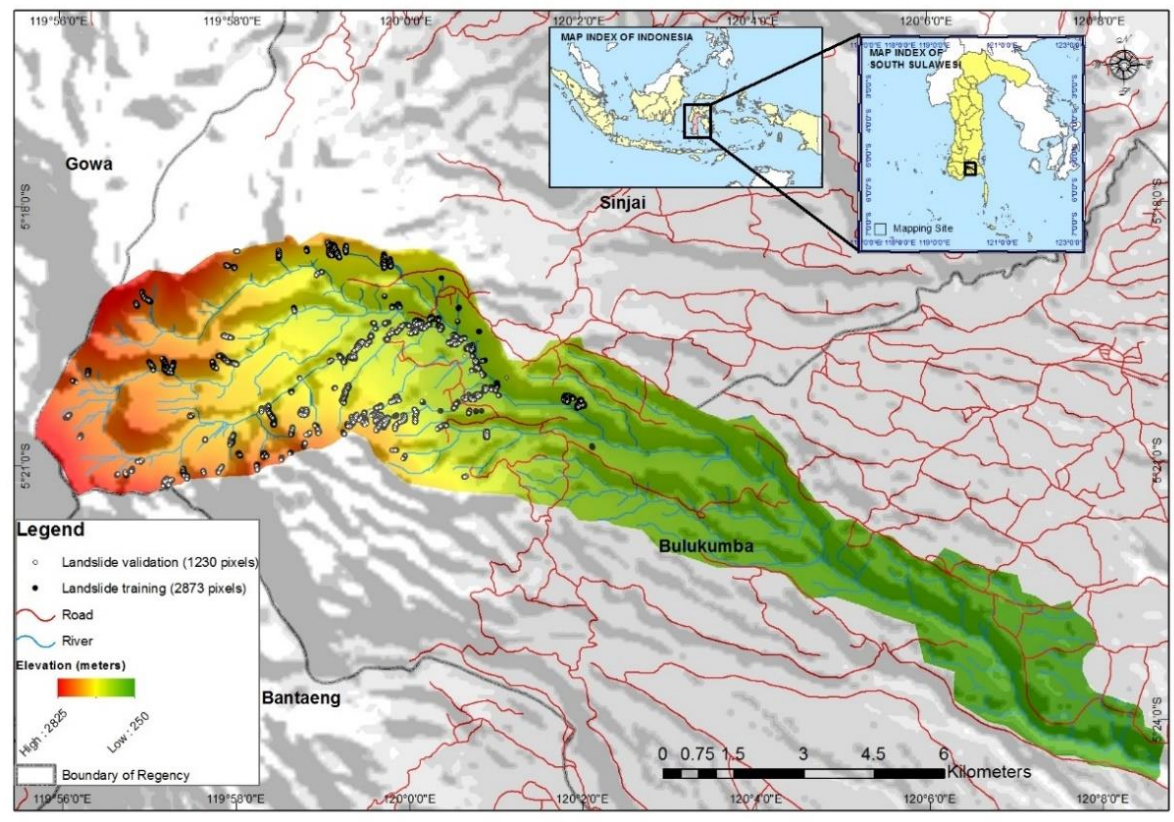

Figure 1. Study area

The tropical climate of South Sulawesi has individual characteristics of the two seasons of the year: the rainy season and dry season. The northeast monsoon Giving raises rainy season between November and July (March to July has the maximum precipitation), and the southwest monsoon causes the dry season, from August to October. The annual rainfall data were recorded at three stations, i.e., Pasir Putih station, 
Malino station and Tanete/Bulo-bulo station from year 2010 to 2015. The annual rainfall data recorded at Pasir Putih station was 2,976 to 7,114 mm/year with average annual rainfall 4,524 $\mathrm{mm} /$ year. Rainfall recorded at Malino station was 3,271 to 5,346 mm/year with average annual rainfall 3,933 mm/year; and recorded at Tanete/bulo-bulo station was 2,237 to $5,711 \mathrm{~mm} /$ year with average annual rainfall 3,538 $\mathrm{mm}$ /year. The monthly rainfall is more than $400 \mathrm{~mm}$ in the month of December and rises to $627 \mathrm{~mm}$ in July (Agency of Climatology and Geophysical, Makassar, Indonesia, 2016). Due to the increasing intensity of rainfall leading to the possibility of landslides and especially in shallow landslides correspondingly increased with the high-intensity rainfall in a short time (Hasnawir et al., 2017).

\subsection{Preparation of data}

Data selection is the important thing in the preparation of the landslide susceptibility Map. The good data selection for analysis helps to find satisfactory results. Management and collection or selection using Arc GIS 10.3 must be accurate in establishing a spatial data landslide inventory and also a causative factor. For the analysis of the frequency ratio (FR) calculation was carried out using Microsoft Excel, while for the logistic regression (LR) used the program Statistical Package for Social Sciences (SPSS). More detail of the research, it can be consulted in Figure 3.

\subsubsection{Landslide inventory}

Landslides inventory can involve field surveys, expression of morphological, and interpretation of remote sensing images based on spectral characteristics, shape, and contrast (Kanungo et al., 2006). This study used data landslide from 2012 to 2016 using air photography of Google Earth Pro and ground survey (Figure 1 and Figure 2). The purpose was to find a correlation between the occurrence of landslides and land use change from 2004 to 2011 . The study area was limited to the upper of Ujung-Loe Watersheds. A total of 188 landslides were identified covering an area of 43.65 hectares $\left(0.44 \mathrm{~km}^{2}\right)$. Most of the landslides are of the shallow type with minimum and maximum landslide area of $137 \mathrm{~m}^{2}$ and 15,600 $\mathrm{m}^{2}$, respectively. Using the landslide data from the survey and digitizing high-resolution from Google Earth Pro to Arc GIS 10.3 , it digitized the time series imaging data by image interpretation landslide, and these files were saved as GIS compatible format as . $\mathrm{kml}$ (extension). Then, the data was again subsequently changed into shape file and into raster format $10 \times 10$ meter. Figure 2 shows the location of all landslide data divided into two group i.e. landslide for training at 2,873 pixels (70 \%) and a landslide for validation at 1,230 pixels (30 \%).

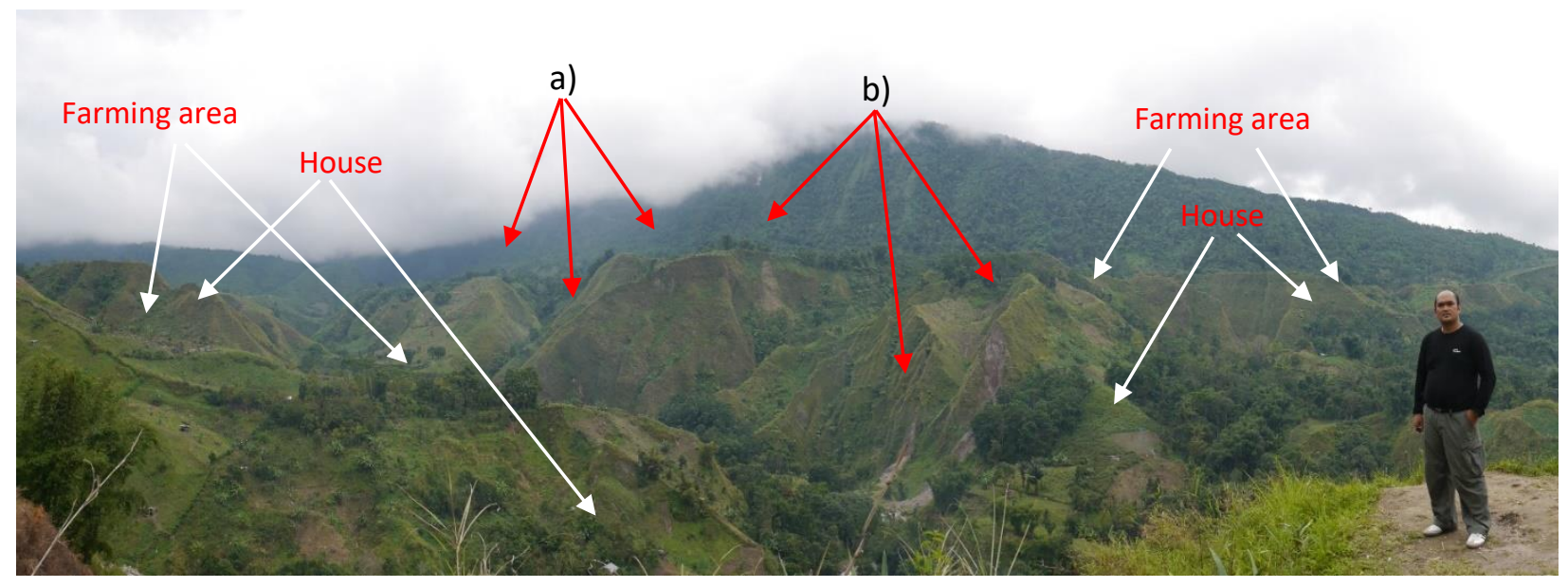

Figure 2. Landslide inventory a) old landslide, b) new landslide

\subsubsection{Landslide causative factors}

In susceptibility map, the most important assumption that the incidence of landslides will occur in the same condition is affected by the cause of the landslides that have been occurred. There are no strict guidelines for the selection of causative factors to be used in logistic regression analysis and certainty factor, and as such, the selected covariates vary widely between studies (Ayalew \& Yamagishi, 2005; Dou et al., 2015). Correspondingly, the determination of landslide causative factors was associated with the availability of data. Therefore, we selected causative factors based on the general knowledge found in 
previous studies and its availability in the target location. The entire landslide causative factors that have been used for the independent variable in the landslide susceptibility mapping (Figure 4). The independent variable was nine (9) causative factors including elevation, slope, aspect, curvature, lithology, and distance from fault, distance to river, drainage density, and land use change (LUC).

Elevation, slope, aspect, and curvature were extracted from contour data digital interval 12.5 meters. Contour data of Rupa Bumi Indonesia (RBI) on map scale 1: 25,000 from Geospatial Information Agency of Indonesia (BIG) was obtained Using arc toolbox raster surface in ArcGIS 10.3, elevation, slope, aspect, and curvature were extracted. Using the uniform isotropic material, increased slope correlates with increased likelihood of failure. In this study, we have used six (6) slope categories $\left(0-10^{\circ}, 10-20^{\circ}, 20-30^{\circ}, 30-40^{\circ}, 40-\right.$ $50^{\circ}$, and above $50^{\circ}$ ) which were considered and represented in the form of slope thematic data layer. Likewise, the aspect map plays a significant role in slope stability assessment (Chauhan et al., 2010). In this study, aspect was divided into nine classes namely, flat, North, Northeast, East, Southeast, South, Southwest, West, and Northwest. Curvature was classified using the curvature of the profiles into three categories: concave, flat and convex. The values represented the morphology topography curvature. In the case of profile curvature, it was related to the puddle condition after heavy rain. Moreover, the reason is that, following heavy rainfall, a more upwardly concave or convex slope has more water and retains it longer (Lee \& Lee, 2006).

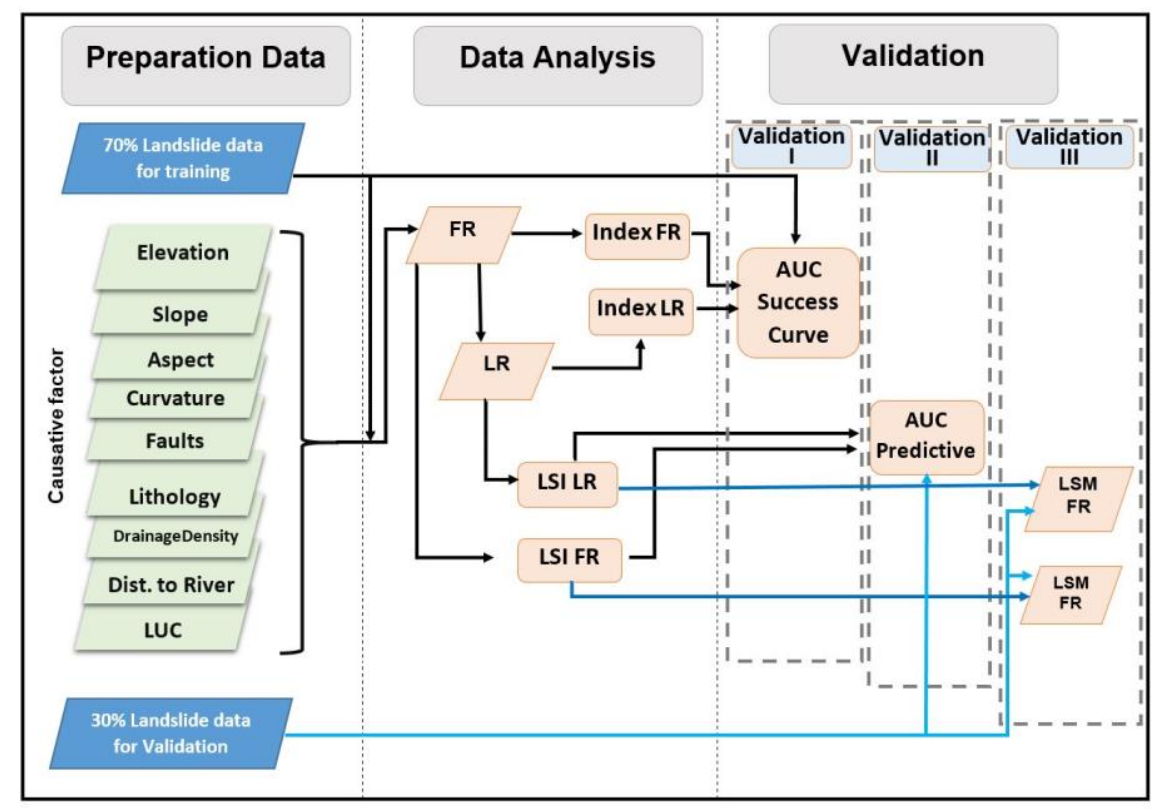

Figure 3. Research framework

The geology of the area was using digital data produced by Indonesia Government, namely Geology Map by Geological Research Institute, at a scale of 1:250,000. This map includes the current study area. The geology data consist of lithology, structure (fault or lineament), and rock type. Lithology is the primary data or parameters for analysis of the landslide map. Lithology is a standard variable that controls the landslide danger. It related to the strength of the material, because lithological composition and structure vary for different types of rocks (Kanungo et al., 2006). In addition, resistance to the driving force depends on the strength of rocks and stones that will be more resistant. Faults are structural features, which describes the zones/areas of weakness, fractures, and among lineament going higher susceptibility to landslides. It has been observed that the increased probability of landslide occurrence in a location close to faults not only affect the surface structure of the material but equally contributes to the permeability and cause slope instability. For this purpose, the distance from faults was used to analyze the incidence of landslides at a distance of faults. The proximity of the fault was obtained by buffering the map of faults (Rasyid, Bhandary, \& Yatabe, 2016).

Both drainage lines and landslide occurrence in the hilly area had a strong association due to erosional activity in this location. The distance from the river has been calculated by buffering analysis of stream 
lines. This information was derived from a topographic map of scale 1:25,000 called Peta Rupa Bumi Indonesia (RBI) prepared by Geospatial Information Agency of Indonesia (BIG) at 2012. The class starts from 0 to $100 \mathrm{~m}$ to $>500 \mathrm{~m}$. Similarly, drainage density was calculated using Arc Toolbox kernel density in $\mathrm{km} / \mathrm{km}^{2}$. The class of drainage density was grouped in five class starting from 0 to $1 \mathrm{~km} / \mathrm{km}^{2}$ to $>4 \mathrm{~km} / \mathrm{km}^{2}$.

Besides topographic factors and geology, land use (cover) is an essential element/factor responsible for landslide occurrences. The incidence of the landslide is inversely related to the vegetation density. This research used land use change (LUC) as vegetation density. LUC was as a new causative factor to change land use pattern to build a landslide susceptibility mapping. To the critical slope, LUC triggered a series of shallow and profound landslides (Mugagga et al., 2012). The LUC map was derived from overlay land use 2004 and land use 2011. Land use was derived from interpretation Landsat 5 TM (date recorded September, 21th 2004) and Landsat 7 ETM+ (time filed October, 11th 2011) images, each with a $30 \mathrm{~m}$ resolution, collected from United States Geological Survey (USGS).
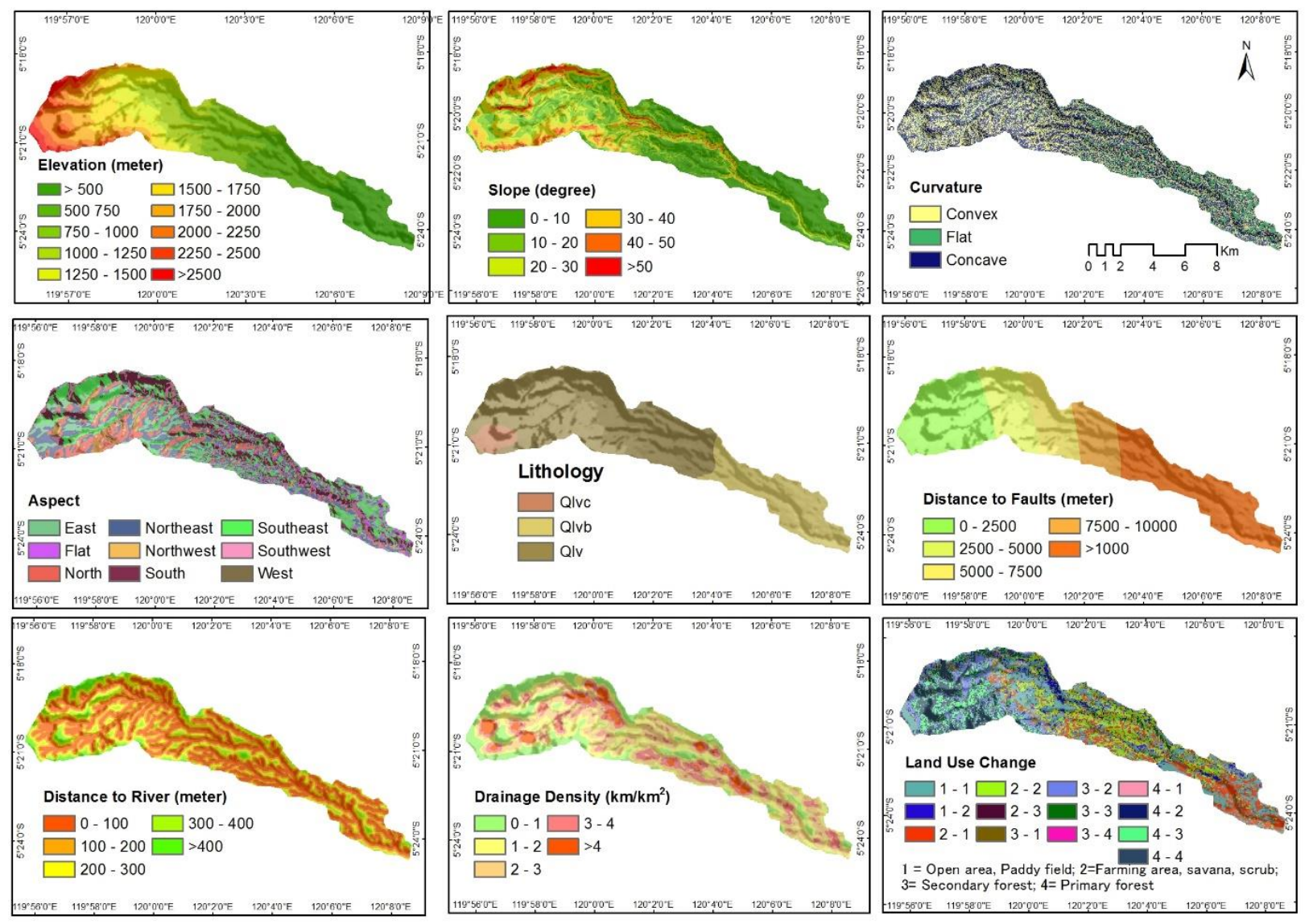

Figure 4. Eleven causative factor of landslide

The unsupervised classification method was applied to classify land use. Unsupervised classification consists of three steps: (1) the map creation of $N$ spectral class using Iterative Self-Organizing Data Analysis Technique Algorithm, (2) the development of land use (LU) map with the help of reference data, and (3) the accuracy measurement of the ratings of all LU reference map using independent data and selection of a map LU with the highest accuracy (Lang et al., 2008). This method was applied to classify land use into seven (7) such as type: open area, paddy field, farming area, scrub, savanna, secondary forest and primary forest (Soma \& Kubota, 2017). Overall accuracy values of LU 2004 and LU 2011 were $86 \%$ and $90 \%$, respectively. Kappa values of 0.83 and 0.88 were achieved for the unsupervised classified maps of LU 2004 and LU 2011, respectively.

Moreover, LUC was built by classifying once more LU 2004 and 2011 in four classes: (1) open area, paddy field, (2) farming area and shrub, savanna, (3) secondary forest and (4) primary forest. In the next step, each other was overlaid using ARC GIS 10.3 and founded 13 classes as a class of LUC. They were $1-1$ (change from open area and paddy field to open area and paddy field) , $1-2$ (change from open area and paddy field to farming area and scrub, savanna), $2-1$ (change from farming area and scrub, savanna to 
open area and paddy field), $2-2$ (change from farming area and scrub, savanna to farming area and scrub, savanna), 2 - 3 (change from farming area and scrub, savanna to secondary forest), $3-1$ (change from secondary forest to open area and paddy field), $3-2$ (change from secondary forest to farming area and scrub, savanna), $3-3$ (change from secondary forest to secondary forest), $3-4$ (change from secondary forest to primary forest), $4-1$ (change from primary forest to open area and paddy field), $4-2,4-3$ (change from primary forest to secondary forest), and $4-4$ (change from primary forest to secondary forest), and 4 - 4 (change from primary forest to primary forest). LUC was downgraded from pixel size of 30 x 30 meter to pixel size of $10 \times 10$ meter.

Landslide was described as the dependent variable and causative factor i.e. elevation, slope, curvature, distance to river, drainage density, lithology, and distance to faults. LUC was described as the independent variable. Independent and dependent variables were used as a map input and then processed to turn it into a raster map with a pixel size of $10 \mathrm{~m} \times 10 \mathrm{~m}$. We can observe the causative factor map in Figure 4 . The study area included 795,227 pixels. The landslide data used in the model included 2,873 pixels (70\% of Landslide) and 1,230 pixels (30\%) for validation.

\subsection{Data Analysis}

There are two analyses methods to understand the performance of each causative factor (frequency ratio (FR), and logistic regression) to produce landslide susceptibility map. Frequency ratio analysis was implemented to define the performance of which class each causative factor and logistic regression methods could describe the performance of the susceptibility of landslide occurrence.

\subsubsection{Frequency Ratio}

The landslide and the causes were related and it can be concluded between areas where the landslide occurs with the causative factors of landslides. Simple statistical techniques to determine the closeness of the relationship has been applied to the frequency ratio (FR) approach. Frequency ratio for each causative factor was calculated by dividing the landslide occurrence rate by the area ratio. If the ratio is bigger than 1.0, the relationship between the landslide and the causative factor is higher, and, if the relationship is less than 1 , the connection is low (Lee $\&$ Lee, 2006). A ratio value in each class shows the level of relationship the frequency ratio value calculated by the Equation (1).

$$
F R=\frac{\operatorname{PxcL}(\mathrm{nm}) / \sum^{\mathrm{PnxL}}}{\operatorname{Pixel}(\mathrm{nm}) / \sum^{\mathrm{Pnx}}}
$$

Where, pixel $(\mathrm{nm})$ number of pixel with landslide within class $\mathrm{n}$ of $\mathrm{j}$ parameter, Pixel $(\mathrm{nm})$ Number of pixel in class $\mathrm{n}$ of $\mathrm{m}$ parameter, $\Sigma \mathrm{PnxL}$ total pixel of $\mathrm{m}$ parameter, and $\Sigma \mathrm{Pnx}$ whole pixel of the area. To create an index susceptibility to landslides, all causative factors were charted in the form of raster maps of the value FR then summed by using Equation (2).

$$
\mathrm{LSI}=\mathrm{FR} 1+\mathrm{FR} 2+\ldots+\mathrm{FRn}
$$

Where FR1, FR2, FR3... FRn is the frequency ratio raster maps of landslide causative factors.

\subsubsection{Logistic regression}

Logistic regression resulted in landslide susceptibility index. A simple introduction to logistic regression available in (Chau \& Chan, 2005) which defines the probability occurrence of landslides divided by the probability of no occurrence of landslides. It is useful to predict the presence or absence of a characteristic or outcome based on values of a set of variable predictors. Generally, in the logistic regression, spatial prediction can be modeled using the independent and the dependent variables (Shirzadi et al., 2012). It is useful when the variable is a binary or dichotomous. Variables can be continuous, or discrete, or a combination of the two types and they do not always have a normal distribution. The probability of regression can be understood as the possibility of state dependent variables. Data analysis created iteration in ten tests using equal data of landslide and no landslide. Using an equal data of occurrence of landslide and no landslide will result better and fair for logistic regression analysis (Rasyid et 
al., 2016). They were restricted to fall within a range of values from 0 to 1 (Xu et al., 2013). The value of zero shows probability of $0 \%$ landslide occurrences, and one shows a $100 \%$ probability (Dai et al., 2004). The logistic regression followed on logistic function $-z$ expressed by the Equation (3).

$$
\begin{gathered}
P=\frac{1}{1+\exp ^{-\mathrm{Z}}} \\
\mathrm{Z}=\mathrm{C}_{0}+\mathrm{C}_{1} \mathrm{CF}_{1}+\mathrm{C}_{2} \mathrm{CF}_{2}+\ldots+\mathrm{C}_{\mathrm{n}} \mathrm{CF}_{\mathrm{n}}
\end{gathered}
$$

Where $P$ is the probability of landslide occurrence that estimated values varying from 0 to 1 . Variable $Z$ is landslide causative factor and is assumed as a linear combination of the causative factors $X i(i=1,2, \ldots n)$. Moreover, $\mathrm{Z}$ calculates using Equation (4). $\mathrm{C}_{0}$ is the intercept, and $\mathrm{C} 1, \mathrm{C} 2, \ldots, \mathrm{Cn}$ are coefficient, which measures the contribution of independent factors $\left(\mathrm{CF}_{1}, \mathrm{CF}_{2}, \ldots, \mathrm{CF}_{n}\right)$ to the variations in $\mathrm{Z}$.

\subsection{Validation and verification}

In addition to a decrease in prediction of accuracy and probability, validation can improve the reliability. During the modeling predictions, the most important and critical component is to carry out the validation of the results of prediction (Chung \& Fabbri, 2003). In this study, the landslide inventories were divided into two parts; one for training and the other for validation. This study used a 2,873 pixel (70\%) inventories landslides to produce models and 1,230 (30\%) of pixels for validation. The fundamental assumptions election landslide of data for training and validation of the model was randomly taken on each part of landslide occurrence in the area of research and also based on the representation of the landslide area. To illustrate the procedure, a small portion of the landslide-prone areas was selected as the data for validation. Size, area, depth of landslides and distribution significantly varies from place to place. Also, we used the ROC curve to plot predicted probabilities in order to understand the problem of accuracy, selection criteria, and interpretation.

For validating the landslide susceptibility map, AUC curve was used as a measure of overall fit and comparison of modeled prediction. The area determines the success rate under the curve (AUC) of the training data set, and predictable level calculated from the AUC of the validation dataset. ROC curves were used to evaluate the predictive accuracy of the model selected in the statistical approach, such as logistic regression (Gorsevski et al., 2006). The AUC obtained from the ROC plot statistics is the most preferred type that can influence rating (Akgun et al., 2012). Predicted probabilities generated by logistic regression can be seen as an indicator to be continuously compared with a binary response variable observed. In this study, the validation process further demonstrates the level of accuracy of landslide susceptibility map to calculate the ratio of the data for validation of landslides that fall into each class of vulnerability. It was generally assumed that most of the landslides for validation must occur on a high-class to a higher susceptibility $(\mathrm{H}+\mathrm{VH})$.

\section{RESULTS AND DISCUSSION}

\subsection{Frequency Ratio}

Table 1 indicates a correlation between landslide occurrence and each class of landslide causative factors. In the case of the relationship between landslide occurrence and LUC, class of primary forest to open area and paddy field (4-1) had the highest probability of landslide occurrence with frequency ratio 8.70. Moreover, class of secondary forest to the farming area, savanna, scrub (4-2) had frequency ratio 2.20. The vegetation which cause this frequency ratio affects the stability of the slope. Land with forest having the root system would reinforce the soil strength and stabilizes the slope (Kubota, Sanchez-castillo, \& Soma, 2015). Forest clearance seems to have manifested primarily through increased rates of landslide activity (Glade, 2003). 
Table 1. The value of Frequency Ratio and Certainty Factor for each landslide causative factors

\begin{tabular}{|c|c|c|c|c|c|c|}
\hline Factor & Class & Pixel Class* & $\%$ Class & Landslide pixel** & \% Landslide & Frequency Ratio \\
\hline \multirow{10}{*}{ Elevation (meter) } & $<500$ & 126010 & 15.85 & 0 & 0.00 & 0.00 \\
\hline & $500-750$ & 113821 & 14.31 & 0 & 0.00 & 0.00 \\
\hline & $750-1000$ & 117886 & 14.82 & 382 & 13.30 & 0.90 \\
\hline & $1000-1250$ & 99735 & 12.54 & 544 & 18.93 & 1.51 \\
\hline & $1250-1500$ & 80401 & 10.11 & 446 & 15.52 & 1.54 \\
\hline & $1500-1750$ & 73551 & 9.25 & 665 & 23.15 & 2.50 \\
\hline & $1750-2000$ & 62583 & 7.87 & 452 & 15.73 & 2.00 \\
\hline & $2000-2250$ & 63418 & 7.97 & 202 & 7.03 & 0.88 \\
\hline & $2250-2500$ & 38830 & 4.88 & 180 & 6.27 & 1.28 \\
\hline & $>2500$ & 18992 & 2.39 & 2 & 0.07 & 0.03 \\
\hline \multirow[t]{6}{*}{ Slope (degree) } & $0-10$ & 277391 & 34.88 & 233 & 8.11 & 0.23 \\
\hline & $10-20$ & 193490 & 24.33 & 504 & 17.54 & 0.72 \\
\hline & $20-30$ & 142736 & 17.95 & 519 & 18.06 & 1.01 \\
\hline & $30-40$ & 114954 & 14.46 & 613 & 21.34 & 1.48 \\
\hline & $40-50$ & 56795 & 7.14 & 819 & 28.51 & 3.99 \\
\hline & $>50$ & 9861 & 1.24 & 185 & 6.44 & 5.19 \\
\hline \multirow[t]{3}{*}{ Curvature } & Concave & 335269 & 42.16 & 1,614 & 56.18 & 1.33 \\
\hline & Flat & 100826 & 12.68 & 158 & 5.50 & 0.43 \\
\hline & Convex & 359132 & 45.16 & 1,101 & 38.32 & 0.85 \\
\hline \multirow[t]{9}{*}{ Aspect } & Flat & 48980 & 6.16 & 43 & 1.50 & 0.24 \\
\hline & North & 105139 & 13.22 & 963 & 33.52 & 2.54 \\
\hline & Northeast & 140313 & 17.64 & 599 & 20.85 & 1.18 \\
\hline & East & 128555 & 16.17 & 311 & 10.82 & 0.67 \\
\hline & Southeast & 155292 & 19.53 & 191 & 6.65 & 0.34 \\
\hline & South & 127354 & 16.01 & 515 & 17.93 & 1.12 \\
\hline & Southwest & 48881 & 6.15 & 43 & 1.50 & 0.24 \\
\hline & West & 11324 & 1.42 & 23 & 0.80 & 0.56 \\
\hline & Northwest & 29389 & 3.70 & 185 & 6.44 & 1.74 \\
\hline \multirow[t]{3}{*}{ Lithology } & Qlvb & 195818 & 24.62 & 0 & 0.00 & 0.00 \\
\hline & Qlv & 562441 & 70.73 & 2,826 & 98.36 & 1.39 \\
\hline & Qvic & 36968 & 4.65 & 47 & 1.64 & 0.35 \\
\hline \multirow[t]{5}{*}{ Distance to Faults (meter) } & $0-2500$ & 228372 & 28.72 & 913 & 31.78 & 1.11 \\
\hline & $2500-5000$ & 123498 & 15.53 & 1,333 & 46.40 & 2.99 \\
\hline & $5000-7500$ & 106243 & 13.36 & 472 & 16.43 & 1.23 \\
\hline & $7500-10000$ & 92127 & 11.58 & 155 & 5.40 & 0.47 \\
\hline & $>10000$ & 244987 & 30.81 & 0 & 0.00 & 0.00 \\
\hline \multirow[t]{6}{*}{ Distance to River (meter) } & $0-100$ & 325991 & 40.99 & 1,489 & 51.83 & 1.26 \\
\hline & $100-200$ & 240871 & 30.29 & 726 & 25.27 & 0.83 \\
\hline & $200-300$ & 139539 & 17.55 & 397 & 13.82 & 0.79 \\
\hline & $300-400$ & 59549 & 7.49 & 189 & 6.58 & 0.88 \\
\hline & $400-500$ & 19942 & 2.51 & 42 & 1.46 & 0.58 \\
\hline & $>500$ & 9335 & 1.17 & 30 & 1.04 & 0.89 \\
\hline \multirow[t]{5}{*}{ Drainage Density $\left(\mathbf{k m} / \mathrm{km}^{2}\right)$} & $0-1$ & 147677 & 18.57 & 698 & 24.30 & 1.31 \\
\hline & $1-2$ & 228100 & 28.68 & 635 & 22.10 & 0.77 \\
\hline & $2-3$ & 252005 & 31.69 & 829 & 28.85 & 0.91 \\
\hline & $3-4$ & 121676 & 15.30 & 512 & 17.82 & 1.16 \\
\hline & $>4$ & 45769 & 5.76 & 199 & 6.93 & 1.20 \\
\hline \multirow{13}{*}{$\begin{array}{l}\text { LUC } \\
\text { (1=Open area, Paddy area; } \\
\text { 2=Farming area, savanna, } \\
\text { scrub; 3=Secondary Forest; } \\
\text { 4=Primary Forest) }\end{array}$} & $1-1$ & 167966 & 21.12 & 608 & 21.16 & 1.00 \\
\hline & $1-2$ & 44883 & 5.64 & 276 & 9.61 & 1.70 \\
\hline & $2-1$ & 127015 & 15.97 & 134 & 4.66 & 0.29 \\
\hline & $2-2$ & 140425 & 17.66 & 215 & 7.48 & 0.42 \\
\hline & $2-3$ & 3971 & 0.50 & 2 & 0.07 & 0.14 \\
\hline & $3-1$ & 24542 & 3.09 & 157 & 5.46 & 1.77 \\
\hline & $3-2$ & 88061 & 11.07 & 513 & 17.86 & 1.61 \\
\hline & $3-3$ & 30715 & 3.86 & 158 & 5.50 & 1.42 \\
\hline & $3-4$ & 4602 & 0.58 & 26 & 0.90 & 1.56 \\
\hline & $4-1$ & 954 & 0.12 & 30 & 1.04 & 8.70 \\
\hline & $4-2$ & 19912 & 2.50 & 177 & 6.16 & 2.46 \\
\hline & $4-3$ & 55800 & 7.02 & 180 & 6.27 & 0.89 \\
\hline & $4-4$ & 86381 & 10.86 & 397 & 13.82 & 1.27 \\
\hline
\end{tabular}

*Total pixel area 795,227 **Landslide Training 2,873 
In slope class, slope above $20^{\circ}$ has a ratio of $>1$ which indicates a high probability of landslide occurrence. Moreover, slope below $20^{\circ}$ has a ratio of $<1$, which shows a very low probability of landslide occurrence. In class of elevation, the values between 1000 to 2000 meters $(\mathrm{m})$ have indicated a high degree of likelihood of the landslides' occurrence. In the class of curvature, the concave class has a higher probability of landslide occurrence with ratio value $>1$. In the case of the class aspect, north, northwest, south and northeast-facing slopes have frequency ratio $>1$, which shows a high rate of probability of the landslides' occurrence. In the case of lithology, Quarter lompobattang volcanic (QIv) has a ratio of $>1$, which indicates a high probability of landslides' occurrence. Qlv is one of the volcanic and sediment formations in South Sulawesi. Causative factor i.e. distance to fault and rivers, the ratio of the distance/proximity is used to understand the degree of influence on the landslide. Distance to faults below $7500 \mathrm{~m}$ has a ratio $>1$. It shows that more narrow distance to the fault, the probability of landslide occurrence will increase. Similarly, the distance to river below $100 \mathrm{~m}$ has frequency ratio $>1$. It indicates the probability of landslide will increase if the distance to the river is nearer.

To create an index of susceptibility to landslides, all causative factors were mapped in the form of raster maps of the value FR then summed using Equation (2). The index value of frequency ratio of with LUC was in the range of 2.70 to 25.41 and without LUC was in the range of 2.46 to 17.97 (Table 4). The higher LSI value showed greater susceptibility to landslides. The results showed that LUC change creates a higher value than without LUC meaning that LUC is better to predict of landslide occurrence.

\subsection{Logistic regression}

Hence, this study proposes to investigate ten tests to acquire best result and sense of fairness as shown in Table 2 and Table 3. LUC as a new causative factor for landslide had value of 0.589 (number test seventh) that affects landslide occurrence. Forest land with root system would reinforce the soil strength and stabilizes the slope to reduce surface erosion or shallow landslides (Kubota, Sanchez-castillo, \& Soma, 2015). The highest value of 3.081 shows the distance to the river having the greatest effect on landslide occurrence. Moreover, the lowest value of elevation (0.353) indicated a small effect on landslide occurrence in this research.

Table 2. Logistic regression coefficient of landslide causative factors using equal proportion of landslide and non-landslide pixel with LUC causative factor

\begin{tabular}{|c|c|c|c|c|c|c|c|c|c|c|}
\hline \multirow[t]{2}{*}{ Number Test } & \multicolumn{10}{|c|}{ Variable in the equation } \\
\hline & Elevation & Slope & Aspect & Curvature & Lithology & Distance to Faults & Distance to RiverDrain & age Density & LUC & Constant \\
\hline 1 & 0.344 & 0.553 & 0.576 & 0.659 & 1.681 & 0.400 & 3.044 & 1.214 & 0.512 & -10.496 \\
\hline 2 & 0.353 & 0.562 & 0.548 & 0.534 & 1.696 & 0.476 & 3.081 & 0.995 & 0.551 & -10.355 \\
\hline 3 & 0.274 & 0.475 & 0.624 & 0.605 & 1.631 & 0.473 & 2.630 & 1.184 & 0.518 & -9.882 \\
\hline 4 & 0.302 & 0.533 & 0.561 & 0.452 & 1.612 & 0.439 & 2.817 & 0.703 & 0.425 & -9.304 \\
\hline 5 & 0.335 & 0.532 & 0.590 & 0.391 & 1.684 & 0.459 & 2.934 & 1.175 & 0.521 & -10.136 \\
\hline 6 & 0.307 & 0.535 & 0.627 & 0.376 & 1.722 & 0.371 & 2.914 & 0.907 & 0.497 & -9.741 \\
\hline 7 & 0.245 & 0.571 & 0.551 & 0.524 & 1.682 & 0.448 & 2.818 & 0.897 & 0.481 & -9.693 \\
\hline 8 & 0.317 & 0.511 & 0.525 & 0.388 & 1.572 & 0.506 & 2.986 & 0.814 & 0.539 & -9.638 \\
\hline 9 & 0.400 & 0.552 & 0.498 & 0.430 & 1.541 & 0.445 & 3.119 & 0.597 & 0.378 & -9.421 \\
\hline 10 & 0.348 & 0.563 & 0.498 & 0.329 & 1.723 & 0.446 & 2.985 & 0.803 & 0.355 & -9.530 \\
\hline
\end{tabular}

Table 3. Logistic regression coefficient of landslide causative factors using equal proportion of landslide and non-landslide pixel without LUC causative factor

\begin{tabular}{|c|c|c|c|c|c|c|c|c|c|}
\hline \multirow[t]{2}{*}{ Number Test } & \multicolumn{9}{|c|}{ Variable in the equation } \\
\hline & Elevation & Slope & Aspect & Curvature & Lithology & Distance to Faults & Distance to River & Drainage Density & Constant \\
\hline 1 & 0.486 & 0.587 & 0.554 & 0.671 & 1.618 & 0.376 & 2.983 & 1.317 & -10.047 \\
\hline 2 & 0.509 & 0.600 & 0.533 & 0.537 & 1.643 & 0.442 & 3.026 & 1.130 & -9.927 \\
\hline 3 & 0.409 & 0.509 & 0.603 & 0.635 & 1.566 & 0.448 & 2.573 & 1.325 & -9.479 \\
\hline 4 & 0.417 & 0.562 & 0.544 & 0.472 & 1.578 & 0.419 & 2.791 & 0.814 & -9.014 \\
\hline 5 & 0.471 & 0.568 & 0.576 & 0.406 & 1.617 & 0.428 & 2.902 & 1.317 & -9.740 \\
\hline 6 & 0.448 & 0.571 & 0.611 & 0.393 & 1.669 & 0.342 & 2.892 & 1.031 & -9.397 \\
\hline 7 & 0.372 & 0.605 & 0.533 & 0.538 & 1.647 & 0.422 & 2.793 & 1.032 & -9.368 \\
\hline 8 & 0.464 & 0.546 & 0.504 & 0.411 & 1.503 & 0.481 & 2.916 & 0.956 & -9.200 \\
\hline 9 & 0.504 & 0.579 & 0.485 & 0.446 & 1.517 & 0.422 & 3.090 & 0.698 & -9.160 \\
\hline 10 & 0.453 & 0.591 & 0.491 & 0.341 & 1.680 & 0.424 & 2.985 & 0.931 & -9.339 \\
\hline
\end{tabular}




\subsection{Validation}

Table 4 shows results of AUC curve for both success rate and predictive rate for each test. Some landslide and non-landslide pixels were used to obtain AUC success and predictive rate. In general, the AUC of ROC curves representing excellent, good, and valueless tests were plotted on the graph. It classifies the accuracy of a diagnostic test i.e. the value ranges from 0.50 to 0.60 (fail), $0.60-0.70$ (poor), $0.70-0.80$ (fair), 0.80-0.90 (good), and 0.90-1.00 (excellent) (Rasyid et al., 2016). The results showed that the entire test of FR and LR methods both of with and without LUC are included in the good category. The value ranged from 0.833 to 0.854 in success rate and 0.833 to 0.852 in predictive rate, respectively (Table 4 and Fig. 5). Moreover, success rate and predictive rate value for all methods were near to the interval of 0.02 indicating that all the methods were more reliable to a predictive landslide in the future. The proximity of success rate and predictive rate values show how the method helps in landslide prediction in the future (Meten, Prakashbhandary, \& Yatabe, 2015).

Tabel 4. AUC of ROC curve of success and predictive rate and ratio of landslide validation on landslide susceptibility map using FR, and LR Method

\begin{tabular}{|c|c|c|c|c|c|c|c|c|c|c|c|c|}
\hline & \multirow[t]{2}{*}{ Method } & \multirow[t]{2}{*}{ FR } & \multicolumn{10}{|c|}{ Number Test of LR } \\
\hline & & & 1 & 2 & 3 & 4 & 5 & 6 & 7 & 8 & 9 & 10 \\
\hline \multirow[t]{3}{*}{ With LUC: } & AUC Success rate & 0.835 & 0.854 & 0.854 & 0.853 & 0.854 & 0.854 & 0.854 & 0.854 & 0.854 & 0.854 & 0.854 \\
\hline & AUC Predictive rate & 0.834 & 0.852 & 0.852 & 0.851 & 0.852 & 0.852 & 0.852 & 0.852 & 0.852 & 0.851 & 0.852 \\
\hline & $\mathrm{H}+\mathrm{VH}(\%)$ & 79.35 & 80.08 & 80.24 & 78.70 & 79.43 & 79.92 & 80.00 & 80.00 & 79.19 & 79.67 & 79.76 \\
\hline \multirow[t]{3}{*}{ Without LUC: } & AUC Success rate & 0.833 & 0.850 & 0.851 & 0.850 & $0 ., 851$ & 0.850 & 0.850 & 0.851 & 0.850 & 0.850 & 0.851 \\
\hline & AUC Predictive rate & 0.833 & 0.848 & 0.849 & 0.848 & 0.848 & 0.848 & 0.848 & 0.849 & 0.848 & 0.848 & 0.849 \\
\hline & $\mathrm{H}+\mathrm{VH}(\%)$ & 78.46 & 77.97 & 77.56 & 77.24 & 78.38 & 77.40 & 77.97 & 79.19 & 77.07 & 79.19 & 78.94 \\
\hline
\end{tabular}
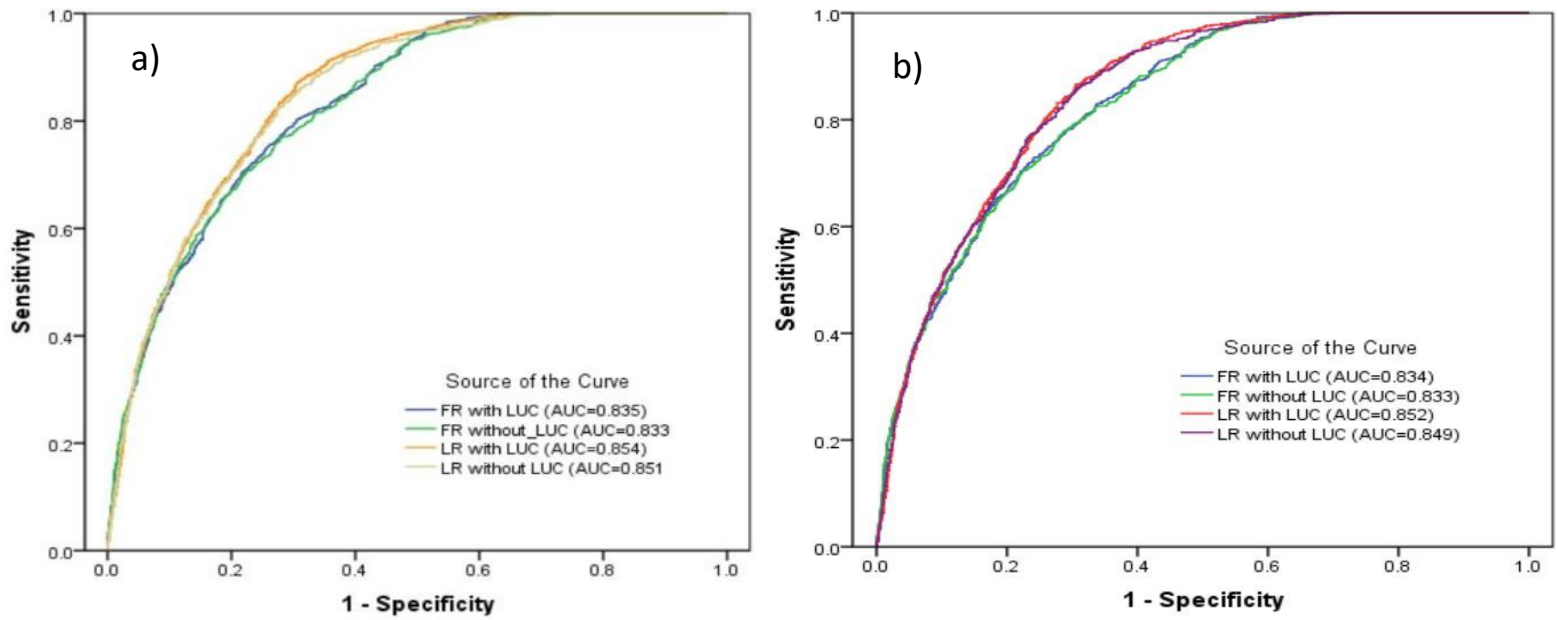

Figure 5. AUC of ROC of landslide susceptibility of with and without LUC causative factor using FR, and LR method; a) success rate and b) predictive rate

In this study, LR method conducted one more validation to choose the best statistical model for creating landslide susceptibility map and the best equation in logistic regression approach from the ten tests. The sum of FR value and equation of the LR models were used to create landslide susceptibility map (LSM). All LSM classes were created by reclassifying LSI of the models using natural breaks method. Overlaid landslide data validation on LSM described another level of accuracy beside AUC curve. The natural breaks method or Jenks optimization method has been widely used especially by planners. It is designed to determine the best arrangement of values into different classes. This approach maximizes the variance between classes and reduces the variation within classes. The description of landslide susceptibility level on location was grouped into five categories, namely very low, low, medium, high and very high. The accuracy of landslide susceptibility map wasverified by a Landslide susceptibility map by overlaying it with $30 \%$ of landslide data 
validation. Validation on LSM for the LR model was better than FR model, and causative factor with LUC was better than without LUC (Figure 5). Validation of FR method with LUC (0.835) in success rate value had slightly higher accuracy than without LUC (0.833). Similarly, theLR method LUC (0.854) had slightly greater accuracy than without LUC (0.851). These show that the FR and LR model with LUC are good model for identifying landslide as opposed to the model without LUC. In the case of AUC curve for predictive rate, FR method with LUC (0.834) value had slightly higher accuracy than without LUC (0.833), and LR method LUC (0.852) had slightly greater than without LUC (0.849). FR and LR model with LUC are better prediction tool for landslide occurrence as opposed to the model without LUC. The curve of the model and validation proves that the susceptibility model is acceptable and the model could be applied to predict the potential landslides in the future. As an interesting point to be noticed in Table 4, the seventh tests for LR had a good result in AUC curve, which is 0.857 in success rate and 0.856 in predictive rate, respectively.

Figure 6 shows the landslide susceptibility map with and without LUC causative factor using FR, and the second test equation of LR model with LUC and seventh test equation of LR without LUC. The LSM by LR model with LUC was obtained using the coefficient values of landslide causative factors as in the Equation (5);

$$
\begin{aligned}
Z= & -10.355+0.353 \text { Elevation + 0.562 Slope + 0.548 Aspect + 0.534 Curvature + } 1.696 \text { Lithology+ } 0.476 \\
& \text { faults + 3.081 Distance to River + 0.995 Drainage density + 0.551 LUC } \ldots \ldots \ldots \ldots \ldots \ldots \ldots \ldots \ldots \ldots \ldots \ldots \ldots \ldots . . .
\end{aligned}
$$

The LSM by LR model without LUC was obtained using the coefficient values of landslide causative factors as in the equation (6);

$$
\begin{aligned}
& Z=-9.368+0.372 \text { Elevation }+0.605 \text { Slope }+0.533 \text { Aspect }+0.538 \text { Curvature }+1.647 \text { Lithology }+0.422 \\
& \text { distance to faults }+2.793 \text { Distance to River }+1.032 \text { Drainage density }
\end{aligned}
$$

The ranges of the index value of each model in five categories were established using natural breaks method. Can et al. (2005) and Bai et al. (2010) stated two important guidance for validating landslide susceptibility map i.e. (1) the high to very high classes should cover only small areas and (2) landslide data validation should lie in high or very high classes.
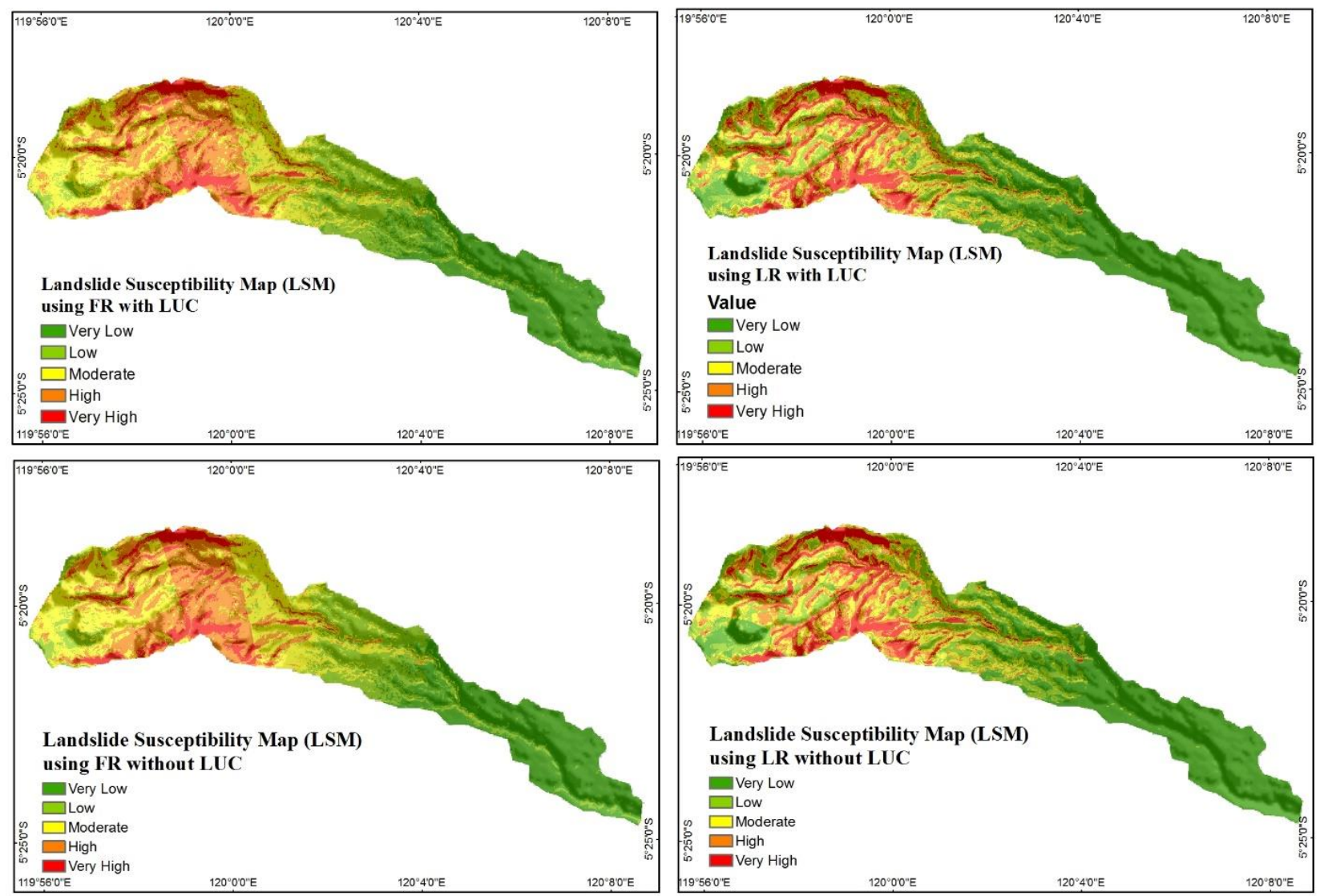

Figure 6. Landslide susceptibility map of with and without LUC causative factors using FR, and LR method 
Table 5 shows the characteristics of susceptibility class for FR and LR models with and without LUC causative factors. It indicates that the ratio of high to very high vulnerability classes cover a small area or less than $32 \%$ for FR and less than $26 \%$ of the total area for LR. The data validation landslide included in the class shows the ratio below $10 \%$. The accuracy of the predicted future landslide from the LSM should have lower ratio in low to very low classes and higher in the high to very high classes (Rasyid et al., 2016). Figure 7 shows high to very high vulnerability classes for LR with LUC $(80.24 \%)$ having a higher value for validation than LR without LUC (79.19\%). Moreover, FR with LUC $(79.35 \%)$ had a higher value than FR without LUC (78.46\%). It indicates that the performance of LUC as a causative factor both using FR and LR model gives a good result. Taken together, the results suggested that changing the vegetation to another landscape causes slopes unstable and increases probability to landslide occurrence.

Table 5. The Characteristic of susceptibility classes on landslide susceptibility map using FR, and LR method with and without LUC causative factor

\begin{tabular}{|c|c|c|c|c|c|c|}
\hline Class Number & Reclassified index value & $\begin{array}{r}\text { Vulnerability } \\
\text { class }\end{array}$ & $\begin{array}{l}\text { Number } \\
\text { of pixels }\end{array}$ & $\begin{array}{l}\% \text { area } \\
\text { covered }\end{array}$ & $\begin{array}{r}\text { Number of } \\
\text { landslide } \\
\text { validation pixel }\end{array}$ & $\begin{array}{l}\% \text { area of landslide } \\
\text { validation covered }\end{array}$ \\
\hline \multicolumn{7}{|c|}{ Frequency Ratio With LUC } \\
\hline 1 & $2.700-5.906$ & Very Low & 187187 & 23.54 & 0 & 0.00 \\
\hline 2 & $5.906-8.578$ & Low & 153294 & 19.28 & 19 & 1.54 \\
\hline 3 & $8.578-10.893$ & Moderate & 208585 & 26.23 & 235 & 19.11 \\
\hline 4 & $10.893-13.476$ & High & 181945 & 22.88 & 452 & 36.75 \\
\hline 5 & $13.476-25.410$ & Very High & 64216 & 8.08 & 524 & 42.60 \\
\hline \multicolumn{7}{|c|}{ Logistic Regression with LUC } \\
\hline 1 & $0.0013-0.1187$ & Very Low & 292856 & 36.83 & 3 & 0.24 \\
\hline 2 & $0.1187-0.3067$ & Low & 162173 & 20.39 & 62 & 5.04 \\
\hline 3 & $0.3067-0.5063$ & Moderate & 133513 & 16.79 & 178 & 14.47 \\
\hline 4 & $0.5063-0.7216$ & High & 113755 & 14.30 & 331 & 26.91 \\
\hline 5 & $0.7216-0.9996$ & Very High & 92930 & 11.69 & 656 & 53.33 \\
\hline \multicolumn{7}{|c|}{ Frequency Ratio Without LUC } \\
\hline 1 & $2.460-5.1971$ & Very Low & 188730 & 23.73 & 0 & 0.00 \\
\hline 2 & $5.1971-7.630$ & Low & 150267 & 18.90 & 24 & 1.95 \\
\hline 3 & $7.630-9.820$ & Moderate & 220097 & 27.68 & 241 & 19.59 \\
\hline 4 & $9.820-12.253$ & High & 178338 & 22.43 & 466 & 37.89 \\
\hline 5 & $12.253-17.970$ & Very High & 57795 & 7.27 & 499 & 40.57 \\
\hline \multicolumn{7}{|c|}{ Logistic Regression without LUC } \\
\hline 1 & $0.0013-0.1187$ & Very Low & 272313 & 34.24 & 4 & 0.33 \\
\hline 2 & $0.1187-0.3067$ & Low & 171069 & 21.51 & 60 & 4.88 \\
\hline 3 & $0.3067-0.5063$ & Moderate & 148090 & 18.62 & 192 & 15.61 \\
\hline 4 & $0.5063-0.7216$ & High & 112403 & 14.13 & 322 & 26.18 \\
\hline 5 & $0.7216-0.9996$ & Very High & 91352 & 11.49 & 652 & 53.01 \\
\hline
\end{tabular}
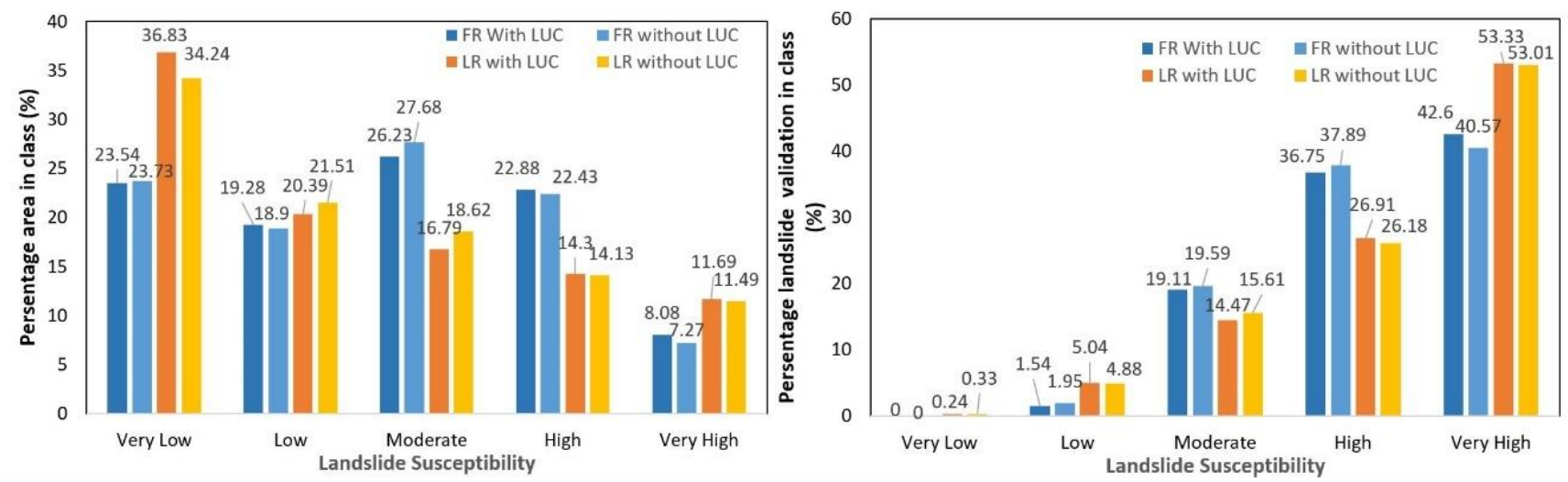

Figure 7. Percentage of landslide susceptibility classes and rate of landslide susceptibility validation on landslide susceptibility of FR and LR method 


\section{CONCLUSION}

In conclusion, land use change (LUC) showed a good demonstration as a new causative factor to build landslide susceptibility map. The result indicated that LUC have the effect to produce LSM. Validation of landslide susceptibility was carried out in this study at both with and without LUC causative factors. Firstly, performances of each landslide model were tested using AUC curve for success and predictive rate. The highest value of predictive rate was at with LUC in both FR and LR methods $(83.4 \%$ and $85.2 \%$, respectively). Secondly, the ratio of landslides on high to very high classes of susceptibility was obtained, which indicates the accuracy level of the method. LR method with LUC had the highest accuracy of $80.24 \%$. These results suggested that changing the vegetation to another landscape causes slopes unstable and increases probability to landslide occurrence.

\section{ACKNOWLEDGMENTS}

The authors thank ESRI Indonesia for supporting the ArcGIS 10.3 in collaboration with Hasanuddin University, Indonesia. This Doctoral program was supported by DIKTI Scholarship Batch 2, 2015.

\section{REFERENCES}

Akgun, A., Sezer, E. A., Nefeslioglu, H. A., Gokceoglu, C., \& Pradhan, B. (2012). An easy-to-use MATLAB program (MamLand) for the assessment of landslide susceptibility using a Mamdani fuzzy algorithm. Computers and Geosciences, 38(1), 23-34. [Crossref]

Ayalew, L., \& Yamagishi, H. (2005). The application of GIS-based logistic regression for landslide susceptibility mapping in the Kakuda-Yahiko Mountains, Central Japan, 65, 15-31. [Crossref]

Bai, S. B., Wang, J., Lü, G. N., Zhou, P. G., Hou, S. S., \& Xu, S. N. (2010). GIS-based logistic regression for landslide susceptibility mapping of the Zhongxian segment in the Three Gorges area, China. Geomorphology, 115(1-2), 23-31. [Crossref]

Can, T., Nefeslioglu, H. A., Gokceoglu, C., Sonmez, H., \& Duman, T. Y. (2005). Susceptibility assessments of shallow earthflows triggered by heavy rainfall at three catchments by logistic regression analyses. Geomorphology, 72(1), 250-271. [Crossref]

Chau, K. T., \& Chan, J. E. (2005). Regional bias of landslide data in generating susceptibility maps using logistic regression: Case of Hong Kong Island. Landslides, 2(4), 280-290. [Crossref]

Chauhan, S., Sharma, M., Arora, M. K., \& Gupta, N. K. (2010). Landslide susceptibility zonation through ratings derived from artificial neural network. International Journal of Applied Earth Observation and Geoinformation, 12(5), 340-350. [Crossref]

Chung, C.-J. F., \& Fabbri, A. G. (2003). Validation of Spatial Prediction Models for Landslide Hazard Mapping. Natural Hazards, 30(3), 451-472. [Crossref]

Dai, F. C., Lee, C. F., Tham, L. G., Ng, K. C., \& Shum, W. L. (2004). Logistic regression modelling of storminduced shallow landsliding in time and space on natural terrain of Lantau Island, Hong Kong. Bulletin of Engineering Geology and the Environment, 63(4), 315-327. [Crossref]

Dou, J., Bui, D. T., Yunus, A. P., Jia, K., Song, X., Revhaug, I., ... Zhu, Z. (2015). Optimization of causative factors for landslide susceptibility evaluation using remote sensing and GIS data in parts of Niigata, Japan. PLOS ONE, 10(7). [Crossref]

Fell, R., Corominas, J., Bonnard, C., Cascini, L., Leroi, E., \& Savage, W. Z. (2008). Guidelines for landslide susceptibility, hazard and risk zoning for land-use planning. Engineering Geology, 102(3-4), 99-111. [Crossref]

García-Ruiz, J. M., Beguería, S., Alatorre, L. C., \& Puigdefábregas, J. (2010). Land cover changes and shallow landsliding in the flysch sector of the Spanish Pyrenees. Geomorphology, 124(3-4), 250-259. [Crossref]

Glade, T. (2003). Landslide occurrence as a response to land use change: A review of evidence from New Zealand. Catena, 51(3-4), 297-314. [Crossref]

Gorsevski, P. V., Gessler, P. E., Boll, J., Elliot, W. J., \& Foltz, R. B. (2006). Spatially and temporally distributed modeling of landslide susceptibility. Geomorphology, 80(3-4), 178-198. [Crossref]

Hasnawir, Kubota, T., Sanchez-Castillo, L., \& Soma, A. S. (2017). The Influence of Land use change and rainfall on shallow landslide in Tanralili Sub-watwrshed, Indonesia. Journal of the Faculty of 
Agriculture, Kyushu University, 62(1), 171-176.

Hedley, J. D., Roelfsema, C. M., Phinn, S. R., \& Mumby, P. J. (2012). Environmental and Sensor Limitations in Optical Remote Sensing of Coral Reefs: Implications for Monitoring and Sensor Design. Remote Sensing, 4(12), 271-302. [Crossref]

Kanungo, D. P., Arora, M. K., Sarkar, S., \& Gupta, R. P. (2006). A comparative study of conventional, ANN black box, fuzzy and combined neural and fuzzy weighting procedures for landslide susceptibility zonation in Darjeeling Himalayas. Engineering Geology, 85(3-4), 347-366. [Crossref]

Kubota, T., Sanchez-castillo, L., \& Soma, A. S. (2015). Root strength of understory vegetation for erosion control on (Micce).

Lang, R., Shao, G., Pijanowski, B. C., \& Farnsworth, R. L. (2008). Optimizing unsupervised classifications of remotely sensed imagery with a data-assisted labeling approach. Computers and Geosciences, 34(12), 1877-1885. [Crossref]

Lee, S., \& Lee, M. J. (2006). Detecting landslide location using KOMPSAT 1 and its application to landslidesusceptibility mapping at the Gangneung area, Korea. Advances in Space Research, 38(10), 22612271. [Crossref]

Meten, M., Prakashbhandary, N., \& Yatabe, R. (2015). Effect of Landslide Factor Combinations on the Prediction Accuracy of Landslide Susceptibility Maps in the Blue Nile Gorge of Central Ethiopia. Geoenvironmental Disasters, 2(1), 1-17. [Crossref]

Mugagga, F., Kakembo, V., \& Buyinza, M. (2012). Land use changes on the slopes of Mount Elgon and the implications for the occurrence of landslides. Catena, 90, 39-46. [Crossref]

Rasyid, A. R., Bhandary, N. P., \& Yatabe, R. (2016). Performance of frequency ratio and logistic regression model in creating GIS based landslides susceptibility map at Lompobattang Mountain, Indonesia. Geoenvironmental Disasters, 3(1), 19. [Crossref]

Shirzadi, A., Saro, L., Hyun Joo, O., \& Chapi, K. (2012). A GIS-based logistic regression model in rock-fall susceptibility mapping along a mountainous road: Salavat Abad case study, Kurdistan, Iran. Natural Hazards, 64(2), 1639-1656. [Crossref]

Soma, A. S., \& Kubota, T. (2017). Land Use Changes on the Slopes and the Implications for the Landslide Occurrences in Ujung-Loe Watersheds South Sulawesi Indonesia. International Journal of Ecology \& Development, 32(2), 33-42.

Xu, C., Xu, X., Dai, F., Wu, Z., He, H., Shi, F., ... Xu, S. (2013). Application of an incomplete landslide inventory, logistic regression model and its validation for landslide susceptibility mapping related to the May 12, 2008 Wenchuan earthquake of China. Natural Hazards, 68(2), 883-900. [Crossref] 